\title{
Inclusion of men in maternal and safe motherhood services in inner-city communities in Ghana: evidence from a descriptive cross-sectional survey
}

Margaret Duah Atuahene ${ }^{1 *}$, Sylvia Arde-Acquah², Nana Frema Atuahene ${ }^{3}$, Martin Adjuik ${ }^{4}$ and John Kuumuori Ganle ${ }^{1}$

\begin{abstract}
Background: There has been a growing realisation of the need to enhance men's inclusion in maternal and safe motherhood services, especially in low-income settings. However, empirical studies on the extent to which men are involved in maternal and safe motherhood services especially in poor inner-city communities are lacking. The purpose of this study was to describe the level of men's inclusion in maternal and safe-motherhood services in inner-city communities in Ghana, and to assess the barriers of men's involvement.

Methods: A descriptive cross-sectional quantitative survey was conducted among a total of 256 randomly selected adult men in Chorkor, an inner-city fishing community in Accra, the capital city of Ghana. A multistage sampling strategy was used to select houses, households and respondents. Descriptive statistical techniques were used to analyse the data. Data analysis was done with the aid of SPSS version 20.

Results: Although almost all (96.6\%) respondents knew the meaning of family planning, as high as 236(92.2\%) have never accompanied their wives/partners to clinics to seek family planning services. Also 242(94.5\%) and 251(98\%) of men, respectively, knew the importance of antenatal services and supervised delivery. However, only 114(44.5\%) of men ever accompanied their wives/partners to seek skilled delivery services. Men's involvement was hindered by barriers such as attitude of health workers, long waiting time and socio-cultural beliefs.

Conclusion: The study revealed a gap between men's awareness of the importance of maternal and safe motherhood services and their actual involvement in accessing these services with their female partners. There is a need to create a supportive environment that encourages men to be involved in maternal health services to help reduce maternal/neonatal morbidity and mortality.
\end{abstract}

Keywords: Men inclusion, Maternal health services, Safe motherhood, Family planning, Spousal communication, Survey, Inner-city communities, Ghana

\footnotetext{
* Correspondence: magat2006@gmail.com

${ }^{1}$ Department of Population, Family and Reproductive Health, School of

Public Health, University of Ghana, P.O. Box LG 13, Legon, Accra, Ghana

Full list of author information is available at the end of the article
}

(c) The Author(s). 2017 Open Access This article is distributed under the terms of the Creative Commons Attribution 4.0 International License (http://creativecommons.org/licenses/by/4.0/, which permits unrestricted use, distribution, and reproduction in any medium, provided you give appropriate credit to the original author(s) and the source, provide a link to the Creative Commons license, and indicate if changes were made. The Creative Commons Public Domain Dedication waiver (http://creativecommons.org/publicdomain/zero/1.0/) applies to the data made available in this article, unless otherwise stated. 


\section{Background}

The inclusion of men in maternal and safe motherhood services is increasingly recognised as an important determinant of women's access to needed care in many lowincome settings, including Ghana [1-5]. Men's inclusion generally means encouraging men to become more involved and supportive of women's needs, choices, and rights in sexual and reproductive health, and addressing men's own sexual and reproductive health needs and behaviour [3, 4]. In this study, we defined men's inclusion in maternal and safe motherhood services to include their involvement in family planning, ANC visits and supervised delivery.

It has been recognised that though maternal and newborn survival requires improvements in basic and comprehensive obstetric care coverage and quality, inclusion of men in maternal and safe motherhood services is required to increase the use of these services, eliminate delays in accessing care, and promote timely referral when problems arise [2-4]. In societies where patriarchal norms are dominant, men are often major decision-makers for the family, hence decisions around when, where and even if a woman should have access to healthcare often are made by men $[1,3,4,6,7]$. Within the context of maternal and safe motherhood services delivery, one study in Tanzania found that households headed by men were associated with more home deliveries [8]. Another study in Pakistan noted that high decisionmaking power by men was linked to low utilisation of antenatal and delivery care services [9]. A number of recent studies in Ghana have also indicated that men's disapproval is a major barrier to women's use of skilled maternal and newborn healthcare services $[2,5]$. In some parts of the world, it has equally been noted that husband's approval is an important determinant of access and use of maternal and safe motherhood services [10,11].

The recognition that men in many low-income contexts play major roles as decision-makers in facilitating or discouraging access to needed maternal and safe motherhood services has led to calls for men to be actively involved in facilitating women's access $[1,2,5]$. In fact, there is growing evidence that involving men in maternal and safe motherhood issues has benefits for timely access to needed services and could significantly influence health outcomes for women and children [10-18]. In Malawi [18] and Uganda [19], men's inclusion in maternal health services is seen as a strategy for getting fast service for women during ANC visits, labour and delivery. In India, one study found that a woman whose husband was involved in her pregnancy was more likely to deliver in a health institution or in the presence of skilled medical personnel at home compared to women whose husbands were not involved [11].
Indeed, the inclusion of men in issues of maternal and safe motherhood is an important component of WHO's recent recommendations on health promotion interventions for maternal and newborn health [20]. Consequently, an increasing number of programmatic efforts and initiatives to actively involve men in maternal and safe motherhood issues are being promoted in many sub-Saharan African contexts where the burden of maternal and child mortality is high and patriarchal norms and values dominant $[3,4]$. At the same time, however, few empirical studies have been conducted to document the extent to which men are involved in issues of maternal health and safe motherhood [3, 4]. In Nigeria, one study found that only $27 \%$ of husbands ever followed their wives to the labour room [21].

A number of studies in Ghana have examined men's attitudes and barriers to male involvement in maternal and child health in a rural context $[3,4,22]$. Some of the barriers to men's involvement include lack of time, long waiting time at health facilities before care is received, and men's perception that pregnancy and childbirth is women's business. Similar barriers have been reported in Nepal [23], Kenya [24], Ethiopia [25] and Malawi [18]. While those studies from Ghana provide insight into men's attitudes toward, and barriers to, male involvement in rural Ghana, these studies were exploratory qualitative studies and did not consider inner-city urban environments, where gender norms and attitudes may be different. This knowledge gap could potentially inhibit programmatic efforts to promote greater inclusion of men in maternal and safe motherhood services delivery in a wide range of contexts including inner-city communities in Ghana. The purpose of this study was to describe the level of men's involvement in maternal and safe-motherhood services in inner-city communities in Ghana, and to assess the barriers to men's involvement.

\section{Methods \\ Study design}

A descriptive cross-sectional quantitative study design was adopted for the study. House-hold survey using interviewer-administered questionnaire was used for data collection.

\section{Study site}

The study was conducted in under-served inner-city communities in Chorkor, Accra. Located on the outskirts of Accra, Chorkor is one of the poorest lowincome, indigenous communities in Accra. According to Ghana's 2010 Population and Housing Census, the population of the community is 344,627 , with an average growth rate of $6.0 \%$ per annum [26]. As a dangerously overpopulated area, Chorkor lacks basic infrastructure such as toilets, bath houses, drains, and roads [27]. 
Houses are generally made of brick, mud and plywood [27]. Educational achievements are very low, and most community members engage in fishing, fish mongering, and fish smoking as their primary occupation [27]. The area frequently experiences communicable disease outbreaks such as cholera, which are mostly related to unhygienic practices. The lack of proper sewage systems and drains causes waste water to run from home to home as children defecate along drains in the community [27]. Additionally, most trash end up on the beach and ocean, which is then later pulled back ashore by fishing nets.

\section{Study population}

The study population was married men who were aged 18 years and above whose wife/partner was pregnant and was in her third trimester or had a child (ren) less than or equal to five years old.

\section{Sampling procedure}

A multi-stage sampling procedure was followed to select houses, households and respondents. First, a simple random sampling technique was employed to select the number of houses (i.e. 256) to be included in the study. There is data from the Ghana Statistical Service specifying house numbers within the Chorkor community. This information was compiled during the 2010 Population and Housing Census. Based on this information, we used an electronic or computer-based number generator to randomly select 256 houses for the study. Second, where any of the randomly selected houses had only one household (defined as a group of people sharing a common dwelling and eating arrangement) with only one male adult who met the inclusion criteria (i.e. aged 18+ and had a wife/partner who was pregnant and was in her third trimester or at least 7 months pregnant or had a child less than or equal to five years old), that household was selected. However, where there were more than one households in a selected house with at least one adult male who met the inclusion criteria, a simple random sampling technique was used to select one household. This was done by giving each household a number (e.g. 1-3). These numbers were then written on pieces of papers, foldered and kept in a bowl. At random, one of the folded pieces of paper was selected and the household corresponding to the selected number was included in the study. Third, where there were more than one adult men in the selected household who met the inclusion criteria, a simple random sampling technique was also used to select only one man. This was again done by giving each man a number (e.g. 1-4). These numbers were again written on pieces of papers, foldered and kept in a bowl. At random, one of the folded pieces of papers was selected and the man corresponding to the selected number was included in the study. Finally, where there were no households with men in the selected house who met the inclusion criteria, the house was replaced with the next house.

\section{Data collection procedure}

A structured, interviewer-administered questionnaire was used to collect the data on socio-demographic variables such as age, education level, income, religion and employment status, participation in family planning, accompanying wives on ANC visit, birth process (labour and delivery). Five field assistants were recruited to collect the data using the house-to-house survey.

An interviewer administered questionnaire was used to collect data. The questionnaire was administered face-to-face by one of the researchers and research assistants.

Prior to the actual data collection, the survey instrument was pre-tested in Kole Gono, an adjourning innercity community with characteristics very similar to Chorkor. This enabled us to detect improperly formulated questions as well as gauge the amount of time needed for each interview. All errors noted during the pre-test were corrected and the survey instrument fully revised before use in the final data collection.

\section{Data analysis}

Data collected were screened by the researchers to check for completeness and consistency of responses. The responses were coded and entered into the Statistical Package for Social Sciences (SPSS) version 20. Results were presented as frequency and percentage distributions.

In addition to socio-demographic variables, a number of variables were also defined and assessed. Men's inclusion in family planning (FP) was assessed by asking respondents to indicate whether they have ever accompanied their wife/partner to an FP Clinic. Men's understanding of FP was also assessed by asking respondents to indicate the most appropriate meaning of FP from a list of possible responses. Other variables included whether men discussed use of FP methods with their wife/partner. In relation to inclusion of men in ANC services, respondents were asked whether they have accompanied their wife/partner (at least once) to ANC clinic during their last/current pregnancy. Respondents' knowledge on the importance of ANC was also evaluated by asking respondents to indicate the most appropriate function of ANC from a list of possible responses. Other variables included whether men knew the health care services provided to pregnant women at $\mathrm{ANC}$, whether men help their wife/partner in her household chores in pregnancy, whether men save money for safe delivery of their wife/partner, and whether men arranged for their wives' transport to ANC-clinics. Finally, a number of 
variables were also assessed in relation to supervised delivery. Specifically, men's inclusion was assessed by asking whether a man accompanied his wife/partner for supervised delivery during their last pregnancy, whether a man will accompany wife/partner to a health facility to deliver in current/future pregnancy, and men's knowledge of the importance of skilled delivery.

\section{Results}

A total of 256 questionnaires were administered. All of them were fully completed and returned, giving a response rate of $100 \%$.

\section{Socio-demographic characteristics of respondents}

Table 1 shows the socio-demographic characteristics of respondents. The mean age of respondents was 35.7 years with a standard deviation of 9.7 years. More than a quarter $102(39.8 \%)$ of the men were aged between 25 and 34 years, followed by men in the age group of 35-44 years $78(30.5 \%)$. With respect to education, 77(30.1\%) had no formal education at all. Furthermore, $115(45 \%)$ of their wives/partners also had no education at all. In relation to occupation, majority of the men were fishermen $125(58.2 \%)$.

\section{Men's involvement in family planning (FP)}

Table 2 displays results on male involvement in family planning. Almost all the men knew something in relation to the meaning of family planning (FP) except one. Of 255 men who knew the meaning of FP, 149(58.4\%) said it was about limiting the number of children, followed by $89(34.9 \%)$ who said it was the spacing of birth intervals. Only $1(0.4 \%)$ said it was a means to destroy marriages. In terms of men's involvement, only 17(6.6\%) have ever accompanied their wives/partners to the FP clinic. Similarly, majority of the respondents $174(68 \%)$ said they did not discuss the use of FP methods with their wives/partners. On current use of FP methods, only $54(21.1 \%)$ of the respondents said their wives/partners were using some methods. Only 16 (6.3\%) did not know if their wives/partners were using FP methods.

\section{Men's inclusion in antenatal care (ANC)}

Table 3 also illustrates men's involvement in ANC. The results show that $209(81.6 \%)$ of the men have never accompanied their wives/partners to visit the ANC clinic. Further analysis of the data (not shown here) showed that of the $47(8.4 \%)$ men who have ever accompanied their wives/partners to ANC, $19(40.4 \%)$ did so only once, 24(51.1\%) went twice and only 4(8.5\%) went at least four times. Similarly, out of the 209 men who never accompanied their wives to ANC-clinics, 134 (64.1\%) and 47 (22.5\%), respectively, cited ANC as being the
Table 1 Socio-demographic characteristics of respondents

\begin{tabular}{|c|c|c|}
\hline Variable & Frequency, $n=256$ & Percentage (\%) \\
\hline \multicolumn{3}{|l|}{ Age of man (years) } \\
\hline $19-24$ & 25 & 9.8 \\
\hline $25-34$ & 102 & 39.8 \\
\hline $35-44$ & 78 & 30.5 \\
\hline $45-54$ & 40 & 15.6 \\
\hline $55-64$ & 10 & 3.9 \\
\hline $65+$ & 1 & 0.4 \\
\hline \multicolumn{3}{|l|}{ Educational level of man } \\
\hline None & 77 & 30.1 \\
\hline Primary & 55 & 21.5 \\
\hline Junior High/middle School & 83 & 32.4 \\
\hline Senior High School & 30 & 11.7 \\
\hline Tertiary & 11 & 4.3 \\
\hline \multicolumn{3}{|l|}{ Educational level of wife/partner } \\
\hline None & 115 & 44.9 \\
\hline Primary & 38 & 14.8 \\
\hline Junior High/middle School & 80 & 31.3 \\
\hline Senior High School & 23 & 9.0 \\
\hline Tertiary & 0 & 0.0 \\
\hline \multicolumn{3}{|l|}{ Marital status } \\
\hline Currently married & 215 & 84.0 \\
\hline Co-habitation & 28 & 10.9 \\
\hline Divorced/separated & 13 & 5.1 \\
\hline \multicolumn{3}{|l|}{ Number of wives/partners } \\
\hline One & 200 & 78.1 \\
\hline Two & 44 & 17.2 \\
\hline Three & 12 & 4.7 \\
\hline \multicolumn{3}{|c|}{ Currently staying with wife/partner } \\
\hline Yes & 149 & 58.2 \\
\hline No & 107 & 41.8 \\
\hline \multicolumn{3}{|l|}{ Occupation } \\
\hline Fishing & 125 & 48.8 \\
\hline Trading/business & 56 & 21.9 \\
\hline Government salary worker & 27 & 10.5 \\
\hline Private salary worker & 47 & 18.4 \\
\hline Unemployed & 1 & 0.4 \\
\hline \multicolumn{3}{|l|}{ Religion } \\
\hline Christianity & 223 & 87.1 \\
\hline Islam & 6 & 2.3 \\
\hline Traditional & 27 & 10.5 \\
\hline \multicolumn{3}{|l|}{ Number of children } \\
\hline $0-4$ & 180 & 70.3 \\
\hline $5-9$ & 69 & 27.0 \\
\hline $10-13$ & 7 & 2.7 \\
\hline
\end{tabular}


Table 1 Socio-demographic characteristics of respondents (Continued)

\begin{tabular}{lll}
\hline Variable & Frequency, $n=256$ & Percentage (\%) \\
\hline Wife/partner has NHIS card & & \\
Yes & 169 & 66.0 \\
No & 84 & 32.8 \\
Don't know & 3 & 1.2 \\
\hline
\end{tabular}

responsibility of the woman, and they being busy with work as their reasons. Only $15(7.2 \%)$ and $13(6.2 \%)$, respectively, cited shyness, and wife feeling uncomfortable going to the ANC with them, as their reasons.

Notwithstanding the relatively low involvement of men, most of them had some understanding of the importance of ANC. Specifically, 118(48.8\%) of the respondents said that ANC may ensure safe delivery; 61(25.2\%) said it monitors the growth of the foetus; $43(17.8 \%)$ said it ensures good health and proper care of women; and 20(8.3\%) said ANC may identify and prevent pregnancy complications. Also, 245(95.7\%) of the men reported that their wives/partners attended ANC at least once during their current or most recent pregnancy. However, 180(74.4\%) men did not know the kind of healthcare services that was provided to pregnant women, including their wives/partners, at ANC clinics.

Other forms of involvement, including saving money towards safe delivery and arranging transport for their wife/partner to visit ANC clinic, were also assessed. Most respondents 254(99.2\%) saved money for safe delivery of their wives/partners (Table 3). Also 216(84.4\%) of the men reported to arrange transport for their wives to visit ANC clinics for check-up.

\section{Men's inclusion in supervised delivery}

Table 4 shows that more than half $142(55.5 \%)$ of the respondents did not accompany their wife/partner for delivery in a health facility during her last pregnancy. When asked whether they will accompany their wife/ partner to the health facility for delivery in the future, only $56(21.9 \%)$ men answered yes.

Despite the relatively low levels of men's involvement in supervised delivery, most of them knew that supervised delivery was important. Majority 174(69.3\%) said supervised delivery is safer for mother and child while $45(17.9 \%)$ said it helped to avoid and/ or address complications during delivery. More than a quarter of the men $(95,37.1 \%)$ said their mothers-in-law decided on the place of delivery, while $79(30.9 \%)$ indicated that both they and their wives/partners jointly chose the place of delivery. Only $2(0.8 \%)$ of the men said their wives/partners made the decision alone.

\section{Barriers to men's inclusion in safe motherhood services} Most respondents $(220,85.9 \%)$ reported that long waiting time at health facilities before care is given was a barrier to their involvement in safe motherhood services. Other important barriers included poor attitude of health workers (197, 77\%), lack of time to accompany spouses $(214,83.6 \%)$, and the fact that some safe motherhood services focused exclusively on women (180, 70.3\%). However, majority of the respondents

Table 2 Men's Inclusion in Family Planning activities

\begin{tabular}{|c|c|c|}
\hline Variable & Frequency & Percentage \\
\hline \multicolumn{3}{|l|}{ Ever accompanied wife/partner to FP Clinic } \\
\hline Yes & 17 & 6.6 \\
\hline No & 236 & 92.2 \\
\hline \multicolumn{3}{|l|}{ Participants' understanding of FP $(n=255)$} \\
\hline Spacing the birth intervals of children & 89 & 34.9 \\
\hline Limiting the number of children & 149 & 58.4 \\
\hline A means by 'the white man' to reduce the population of Africans & 9 & 3.5 \\
\hline It is a means to give power to women & 7 & 2.7 \\
\hline It is a means to destroy marriages & 1 & 0.4 \\
\hline \multicolumn{3}{|l|}{ Discuss use of FP methods with wife/partner? } \\
\hline Yes & 79 & 30.8 \\
\hline No & 174 & 68.0 \\
\hline Not applicable & 3 & 1.2 \\
\hline \multicolumn{3}{|l|}{ Wife/partner currently using any FP methods? } \\
\hline Yes & 54 & 21.1 \\
\hline No & 186 & 72.7 \\
\hline Don't know & 16 & 6.3 \\
\hline
\end{tabular}


Table 3 Men Inclusion in Antenatal Care activities

\begin{tabular}{|c|c|c|}
\hline Variable & Frequency & Percentage \\
\hline \multicolumn{3}{|l|}{$\begin{array}{l}\text { Wife/partner attended (at least once) ANC during } \\
\text { last/current pregnancy }\end{array}$} \\
\hline Yes & 245 & 95.7 \\
\hline No & 2 & 0.8 \\
\hline Don't know & 9 & 3.5 \\
\hline \multicolumn{3}{|l|}{$\begin{array}{l}\text { Accompany wife/partner (at least once) to ANC clinic } \\
\text { during last/current pregnancy }\end{array}$} \\
\hline Yes & 47 & 8.4 \\
\hline No & 209 & 81.6 \\
\hline \multicolumn{3}{|l|}{ Respondents' knowledge on importance of ANC $(n=242)$} \\
\hline Ensures safe delivery & 118 & 48.8 \\
\hline Identify and prevent pregnancy complications & 20 & 8.3 \\
\hline Monitors the growth of the foetus & 61 & 25.2 \\
\hline Ensures good health and proper care of woman & 43 & 17.8 \\
\hline \multicolumn{3}{|l|}{$\begin{array}{l}\text { Know health care services provided to pregnant women } \\
\text { at ANC }(n=242)\end{array}$} \\
\hline Yes & 62 & 25.6 \\
\hline No & 180 & 74.4 \\
\hline \multicolumn{3}{|l|}{ Helps wife in her household chores in pregnancy } \\
\hline Yes & 135 & 52.7 \\
\hline No & 121 & 47.3 \\
\hline \multicolumn{3}{|l|}{ Household chores in which man assists wife $(n=135) ?$} \\
\hline Washing clothes/dishes & 114 & 84.4 \\
\hline Cooking & 13 & 9.6 \\
\hline Bathing older children & 8 & 5.9 \\
\hline \multicolumn{3}{|l|}{ Save money for safe delivery of wife/partner? } \\
\hline Yes & 254 & 99.2 \\
\hline No & 2 & 0.8 \\
\hline \multicolumn{3}{|c|}{ Arrange for transportation for wife to go to health facility for ANC } \\
\hline Yes & 216 & 84.4 \\
\hline No & 40 & 15.6 \\
\hline
\end{tabular}

disagreed that distance to health facilities $(148,57.8 \%)$, cost of services $(144,56 \%)$, lack of information/knowledge about maternal and safe motherhood services $(133,52 \%)$, shyness to take part in maternal and motherhood services (180, 70.3\%), and dissatisfaction with services in health facilities $(157,61.3 \%)$ were barriers to their involvement (see Table 5).

\section{Discussion}

\section{Main results}

This study is one of the few to have focused on the inclusion of men in maternal and safe motherhood services in an inner-city in urban Ghana. The study revealed that most of the men correctly recognised the benefits of FP, ANC and skilled delivery care. About 35\% and $58 \%$ of men, respectively, understood FP to mean only limiting the number of desired children by a couple, and birth spacing between children. This is similar to findings from a study in Nigeria, where $38 \%$ and $35 \%$ of men cited control of family size and birth spacing respectively as the importance of FP [21]. Similarly, and in relation to ANC, most of the men recognised the importance of ANC during pregnancy. This is consistent with findings from Papua New Guinea where $84 \%$ of men considered ANC as important, and knew the benefits of ANC during pregnancy [28]. Furthermore, the study also revealed that most of the men $(174,69.3 \%)$ knew that supervised delivery could ensure safer birth for mother and survival of the child.

Despite men's recognition of the importance of the three domains of maternal and safe motherhood services examined in the study, majority of them were not 
Table 4 Men inclusion in supervised delivery activities

\begin{tabular}{lcc}
\hline Variable & Frequency & Percentage \\
\hline Accompanied wife/partner for supervised delivery & 114 & 44.5 \\
Yes & 142 & 55.5 \\
No & 32 & 12.7 \\
Respondents' knowledge on importance of supervised delivery \\
Woman gets the best of care & 45 & 17.9 \\
Avoids complications & 174 & 69.3 \\
It is safer for mother and child & & \\
Will accompany wife/partner to health facility to deliver in current/future \\
pregnancy \\
Yes & 56 & 21.9 \\
No & 200 & 78.1 \\
Decision-maker on place of delivery & & 31.3 \\
Husband & 80 & 0.8 \\
Wife & 2 & 30.9 \\
Both husband and wife & 79 & 37.1 \\
Mother-in-law & 95 & \\
\hline
\end{tabular}

actively involved in a number of key FP, ANC and supervised delivery services. While the relatively high level of men's recognition of the functions of FP could be attributed to extensive media publicity and education by health workers and partners in the country, only about $17(7 \%)$ men have ever accompanied their wives/partners to an FP clinic. This proportion is far lower than results from a Nigerian study in which $29 \%$ of men accompanied their wives to FP clinics [21]. This relatively low level of men's involvement in FP is importantly further reflected in the fact that $174(68 \%)$ did not discuss issues of FP with their wives/partners. The revelation that more than two-thirds of the men do not discuss use of FP with their spouses is clearly concerning as spousal communication has been found to improve use of FP services among couples. Lack of spousal communication about the use of any FP methods by one's partner could easily lead to suspicion, petty quarrels and gender-based violence. Perhaps this is part of the reasons why only $21.1 \%$ of the wives/partners currently used any FP methods.

But it is not only in the context of FP that male involvement is low. Results relating to men's inclusion in ANC services also suggest that although some men are actively engaged in saving money for safe delivery as well as arranging transport for visit to ANC clinics, the majority had never accompanied their wives/partners to visit the ANC clinic. This relatively low involvement of men was reflected in men's knowledge of ANC services received at ANC clinics. As regards supervised delivery, a similarly low level of men's involvement was observed. What is even worrying is the observation that only $22 \%$ of the men said they would accompany their wife/partner to a health facility for delivery in future. These results are however not surprising: previous studies in the Jinja District of Uganda [29] and a Nigerian community [21] have, respectively, found that only $43.4 \%$ and $27 \%$ of men, accompanied their wives to the health facility for delivery during her most recent delivery.

The relatively low involvement of men was framed by several contextual, social, economic and gender-related factors. For instance, 220(86\%) men reported long waiting time at health facilities before care is given as a barrier to their involvement in safe motherhood services. In Ethiopia [25], Uganda [29], and Ghana [3, 4], similar results have been documented: waiting time of more than $30 \mathrm{~min}$ in a hospital prevented men from accompanying their wives to health facilities. Time is particularly important in the context of Chorkor where economic and social living conditions are harsh and where men - who are usually the bread winners - have to spend long hours at sea fishing. This suggests a need for interventions such as expansion of FP and ANC service delivery points as well as individual booking systems to reduce the amount of time women have to spend before care is

Table 5 Barriers to men's inclusion in safe motherhood services

\begin{tabular}{|c|c|c|}
\hline Variable/Statement & Agree, $n(\%)$ & Disagree, $\mathrm{n} \%)$ \\
\hline Long waiting time in health facilities & $220(85.9)$ & $36(14.1)$ \\
\hline Distance to health facilities & $108(42.2)$ & $148(57.8)$ \\
\hline Attitude of health workers & $197(77.0)$ & $59(23.0)$ \\
\hline Cost of services & $112(44.0)$ & $144(56.0)$ \\
\hline Lack of time to accompany spouse for the services & $214(83.6)$ & $42(16.4)$ \\
\hline Cultural beliefs & $158(61.7)$ & $98(38.3)$ \\
\hline Religious beliefs & $42(16.4)$ & $214(83.6)$ \\
\hline Lack of information/knowledge on safe motherhood/ reproductive health service & $123(48.0)$ & $133(52.0)$ \\
\hline Some safe motherhood services are mainly focused on women only & $180(70.3)$ & $76(29.7)$ \\
\hline Shyness to take part in safe motherhood services as a man & $76(29.7)$ & $180(70.3)$ \\
\hline Dissatisfaction with the safe motherhood services rendered in health facilities & $99(38.7)$ & $157(61.3)$ \\
\hline
\end{tabular}


received. This may encourage men to actively support their wives/partners to receive needed FP, ANC and supervised delivery services.

Another factor that could explain men's relatively low involvement in maternal and safe motherhood services in Chorkor relates to the attitude of health workers, which more than three-quarters expressed dissatisfaction with. Attitude of health workers as a barrier has been reported in several studies [1-5, 7-13]. Attitude of health workers has a particularly huge influence on health care services utilization more generally and men's involvement in maternal and safe motherhood services precisely because clients expect respect from their health care providers. When clients are scorned or disrespected by their healthcare providers, they may never want to visit or return to such service providers. The issue of respect is particularly critical in a largely patriarchal context like Ghana where men expect respect from women. If men are to be actively involved in FP, ANC and supervised delivery services in contexts such as Ghana, there is a need for service providers to be trained in basic interpersonal communication skills so as to enable them provide more supportive and respectful services to couples.

Cultural beliefs have also been revealed in this study to act as barriers to male involvement. In some Ghanaian and African societies, men who engage in some form of safe motherhood services are mocked by their peers. They say such men are 'weak' and controlled by their wives, hence men who are unable to withstand the name calling and mockery are forced to withdraw $[3,4]$. As shown earlier in relation to FP, many men were of the belief that FP is the sole responsibility of women so that men who accompany their wives to the FP clinic are seen as 'weak' and kowtowing to their wives. This is more likely to be the case given that patriarchal norms are very entrenched in many Ghanaian communities [3, 4]. Indeed, studies have found that men do not accompany their wives to FP clinics precisely because of perceptions that FP is women's business [24].

But many men also felt alienated by some of the services that are being provided to pregnant women. For instance, $180(70 \%)$ of the men reported that some safe motherhood services are focused on women only which do not encourage them to fully take part. This would suggest a need for both continuous community education and couple counselling to correct misconceptions and re-inforce the fact that maternal and safe motherhood services like FP are not solely the business of women. At the same time, there is a need to fashion out more innovative strategies to engage men as active partners beyond the provision of money, arranging transport or assisting in household chores. For example, invitation cards could be used to invite men to routine ANC classes and pregnancy schools to enhance men's understanding of maternal and safe motherhood issues.

\section{Limitations of the study}

Although the results of this study have shown the extent to which men are involved in maternal and safe motherhood issues, the study has certain limitations. Since this was a cross-sectional study, it was impossible to assess cause and effect relationships. Related to this design limitation is the fact that the study was descriptive and did not examine association between socio-demographic or other factors and men's involvement in FP, ANC and supervised delivery services. Future studies should include this. Again, and regarding men's understanding of FP, ANC and supervised delivery, a respondent was asked to choose only one answer they considered the most appropriate from a list of possible answers. While this ensured analytical precision by showing the exact understanding of each respondent, we acknowledge that there may exist two or more appropriate answers. In other words, multiple responses could have been allowed. Finally, the study was only conducted in one out of several low-income inner-city communities in Accra, and also involved relatively small sample size. Therefore, the limitation of generalising these results is acknowledged.

\section{Conclusion}

This study has shown that despite men's recognition of the importance of FP, ANC and supervised delivery services, their involvement in the delivery of FP, ANC and supervised delivery services to their wives/partners is relatively low. Among the factors that militate against men's active involvement are the attitude of health workers, long waiting time in health facilities and sociocultural beliefs. Considering the influence and power of men as decision makers in the utilization of safe motherhood services, there is a need to create a supportive community- and health facility-level environment that encourages men to become actively involved. It is critical to include effective ways of delivering education messages to men by using role models and peers to engage them. Attempts should be made to ensure that FP, ANC and supervised delivery services are organized and delivered in a manner that is more male-friendly, and with appropriate health campaigns to change attitudes and beliefs of men towards becoming more actively engaged in supporting their wives/partners to receive skilled and safe motherhood services.

\section{Abbreviations}

ANC: Antenatal care; FP: Family planning; NHIS: National Health Insurance Scheme; SPSS: Statistical Package for Social Sciences; WHO: World Health Organization 


\section{Acknowledgements}

We acknowledge the support of the District Director of Health Services, as well as our research participants. We also acknowledge the useful suggestions and criticisms of reviewers of earlier drafts of this manuscript

\section{Funding}

No source of funding. Authors relied on their own resources.

\section{Availability of data and materials}

The dataset on which this manuscript is based has been deposited in publicly available repository. The dataset is accessible at: https:// dataverse.harvard.edu/dataset.xhtml?persistentld=doi:10.7910/DVN/MOGZ3L. Personal identifiers such as names have however been excluded to preserve privacy of study respondents.

\section{Authors' contributions}

MDA and SA conceived the study and worked on the research proposal. SA led the field work. MA, MDA and NFA performed statistical analysis. JKG contributed to the interpretation of data. JKG draft the manuscript with NFA. All authors were involved in the revision of the first draft of the manuscript and approved it for submission. JKG worked on the second revision of the manuscript incorporating all reviewer comments/suggestions. All authors again approved the manuscript for submission for publication.

\section{Ethics approval and consent to participate}

Ethical clearance was obtained from the Ghana Health Service's Ethical Review Committee and permission sought from the District Health Administration. Informed written consent was obtained from each participant before the start of interviews. All participants were assured of anonymity, privacy and confidentiality. Participation was voluntary and they were assured that findings will purely be used for research purposes.

\section{Consent for publication}

Not applicable

\section{Competing interests}

The authors declare that they have no competing interests.

\section{Publisher's Note}

Springer Nature remains neutral with regard to jurisdictional claims in published maps and institutional affiliations.

\section{Author details \\ 'Department of Population, Family and Reproductive Health, School of Public Health, University of Ghana, P.O. Box LG 13, Legon, Accra, Ghana. ${ }^{2} \mathrm{~S} c h o o l$ of Public Health, University of Ghana, Accra, Ghana. ${ }^{3}$ Augusta Medical Centre, Waynesboro, Virginia, USA. ${ }^{4}$ INDEPTH Network Secretariat, Accra, Ghana.}

Received: 20 July 2016 Accepted: 22 November 2017

Published online: 14 December 2017

\section{References}

1. Kwambai KT, Dellicour S, Desai M, Ameh AC, Person B, Achieng F, Mason L, Laserson K, ter Kuile FO. Perspectives of men on antenatal and delivery care service utilisation in rural western Kenya: a qualitative study. BMC Pregnancy Childbirth. 2013:13:134

2. Ganle JK, Otupiri E, Parker M, Fitpatrick R. Socio-cultural barriers to accessibility and utilization of maternal and newborn healthcare services in Ghana after user-fee abolition. Int J Maternal Child Health. 2015;3(1):1-14.

3. Ganle JK, Dery I, Manu A. 'If I go with him, I can't talk with other women': understanding women's resistance to men's involvement in maternal and child healthcare in Northern Ghana. Soc Sci Med. 2016;166:195-204.

4. Ganle JK, Dery I. 'What men don't know can hurt women's health: a qualitative study of the barriers to and opportunities for men's involvement in maternal healthcare in Ghana. Reprod Health. 2015;12:93.

5. Ganle JK. Addressing socio-cultural barriers to maternal healthcare in Ghana: perspectives of women and healthcare providers. J Women's Health Issues Care. 2014;3:6
6. Langen TT. Gender power imbalance on women's capacity to negotiate self-protection against HIV/AIDS in Botswana and South Africa. Afr Health Sci. 2005;5(3):188-97.

7. Greene ME, Mehta M, Pulerwitz J, Wulf D, Bankole A, Singh S. Involving men in reproductive health: contributions to development. In: Background paper to the report on public choices, private decisions: sexual and reproductive health and the millennium development goals. New York: UN Millennium Project; 2006

8. Mrisho M, Schellenberg JA, Mushi AK, Obrist B, Mshinda H, Tanner M, Schellenberg D. Factors affecting home delivery in rural Tanzania. Trop Med Int Health. 2007;12(7):862-72.

9. Hou X, Ma N. Empowering women: the effect of women decision-making power on reproductive health services up-take: evidence from Pakistan. Washington, DC: World Bank; 2011

10. Lakhani A. Involvement of husbands in antenatal care: evaluation of Deepak charitable Trust's outreach Programme. In: Raju S, Leonard A, editors. Men as supportive partners in reproductive health: moving from rhetoric to reality. New Delhi: Population Council; 2000. p. 46-7.

11. Pal P. Working with men to improve reproductive health in a Delhi slum. In: Raju S, Leonard A, editors. Men as supportive partners in reproductive health: moving from rhetoric to reality. New Delhi: Population Council; 2000. p. 26-7.

12. Ditekemena J, Koole O, Engmann C, Matendo R, Tshefu A, Ryder R, Colebunders $R$. Determinants of male involvement in maternal and child health services in sub-Saharan Africa: a review. Reprod Health. 2012;9:32.

13. Mullany BC. Barriers to and attitudes towards promoting husbands' involvement in maternal health in Katmandu, Nepal. Soc Sci Med. 2006:62:2798-809.

14. Martin LT, McNamara MJ, Milot AS, Halle T, Hair EC. The effects of father involvement during pregnancy on receipt of prenatal care and maternal smoking. Matern Child Health J. 2007;11:595-602.

15. Alio AP, Salihu HM, Kornosky JL, Richman AM, Marty PJ. Feto-infant health and survival: does paternal involvement matter? Matern Child Health J. 2010;14:931-7.

16. Mullany BC, Becker S, Hindin MJ. The impact of including husbands in antenatal health education services on maternal health practices in urban Nepal: results from a randomized controlled trial. Health Educ Res. 2007:22:166-76.

17. Nyondo AL, Choko TA, Chimwaza FA, Muula SA. Invitation cards during pregnancy enhance male partner involvement in prevention of mother to child transmission (PMTCT) of human immunodeficiency virus (HIV) in Blantyre, Malawi: a randomized controlled open label trial. PLoS One. 2015; 10(3):e0119273.

18. Kululanga L, Sundby J, Malata A, Chirwa E. Striving to promote male involvement in maternal health care in rural and urban settings in Malawi a qualitative study. Reprod Health. 2011;8:36

19. Byamugisha R, Tumwine J, Semiyaga N, Tylleskar T. Determinants of male involvement in the prevention of mother-to-child transmission of HIV programme in eastern Uganda: a cross-sectional survey. Reprod Health. 2010;7:12

20. World Health Organization. WHO recommendations on health promotion interventions for maternal and newborn health. Geneva: World Health Organization; 2015.

21. Adenike OBI, Asekun-Olarinmoye EO, Adefisoye AO, Adeleye AA, Sunday OO. Perception, attitude and involvement of men in maternal health care in a Nigerian community. J Public Health Epidemiol. 2013;5(6):262-70.

22. Dumbaugh M, Tawiah-Agyemang C, Manu A, Asbroek G, Kirkwood B, Hil Z. Perceptions of, attitudes towards and barriers to male involvement in newborn care in rural Ghana, West Africa: a qualitative analysis. BMC Pregnancy Childbirth. 2014;14:269.

23. Bhatta DN. Involvement of males in antenatal care, birth preparedness, exclusive breast feeding and immunizations for children in Kathmandu, Nepal. BMC Pregnancy Childbirth. 2013;13:14.

24. Onyango MA, Owoko S, Oguttu. Factors that influence male involvement in sexual and reproductive health in Western Kenya: a qualitative study. Afr $J$ Reprod Health. 2010;14(4):33-44.

25. Asefa F, Geleto A, Dessie Y. Male partners involvement in maternal ANC care: the view of women attending ANC in Hararipublic health institutions, eastern Ethiopia. Sci J Public Health. 2014;2(3):182-8.

26. Ghana Statistical Service. Ghana population and housing census 2010 Accra: Ghana Statistical Service; 2012. 
27. Dako-Gyeke M, Kofie HM. Factors influencing prevention and control of malaria among pregnant women resident in urban slums, Southern Ghana. Afr J Reprod Health. 2015;19(1):44-53.

28. Kura S, Vince J, Crouch-Chivers P. Male involvement in sexual and reproductive health in the Mendi district, Southern highlands province of Papua New Guinea: a descriptive study. Reprod Health. 2013;10(46):1-10.

29. Nantamu PD. Factors Associated With Male Involvement in Maternal Health Care Services in Jinja District, Uganda. Dissertation. School of Public Health 2011. Makerere University.

Submit your next manuscript to BioMed Central and we will help you at every step:

- We accept pre-submission inquiries

- Our selector tool helps you to find the most relevant journal

- We provide round the clock customer support

- Convenient online submission

- Thorough peer review

- Inclusion in PubMed and all major indexing services

- Maximum visibility for your research

Submit your manuscript at www.biomedcentral.com/submit
Biomed Central 